\title{
VERSO E TRADUÇÃO NO SÉCULO DE OURO ${ }^{1}$
}

\author{
José María Micó ${ }^{1}$ \\ 1'Universitat Pompeu Fabra, Facultat d'Humanitats, Barcelona, Espanha
}

\begin{abstract}
Tradução de Andréa Cescoํㅛ
Mara Gonzalez Bezerra²

${ }_{2}^{2}$ Universidade Federal de Santa Catarina, Florianópolis, Santa Catarina, Brasil
\end{abstract}

\begin{abstract}
Resumo: Neste trabalho, pretendeu-se demonstrar como as múltiplas relações existentes entre as noções de adaptação, imitação e tradução de poesia ainda podem ser enriquecidas se considerada a seleção de diferentes versos e estrofes na literatura receptora. Os exemplos foram extraídos de tradutores espanhóis do Século de Ouro: Juan del Encina, Fray Luis de León e Francisco Sanchez de las Brozas (Virgílio); Jerónimo de Urrea (Ariosto); Baltasar de Romaní e Jorge de Montemayor (Ausiàs March); Góngora e Francisco Faría (Claudiano).

Palavras-chave: Tradução de Poesia; Poesia Espanhola do Século de Ouro; Traduções ao Castelhano no Século de Ouro; Verso; Estrofe
\end{abstract}

\footnotetext{
${ }^{1}$ Artigo publicado na Quaderns. Revista de traducció 7, 2002 83-94. A presente tradução foi autorizada para ser publicada em português pela Quaderns. Revista de traducció e pelo autor José María Micó (Universitat Pompeu Fabra. Facultat d'Humanitats Ramon Trías Fargas, Barcelona, Espanha), aos quais agradecemos respeitosamente. A referência bibliográfica completa do artigo original: Micó, José María. "Verso y traducción en el Siglo de Oro". Quaderns: revista de traducció, $\mathrm{n}^{0} 7$ - Dossier. Modalitats històriques de la traducció literària, 2002, p. 83-94. Disponível em: http://www.raco.cat/index.php/quadernstraduccio/article/ viewFile/25308/25143.
}

Esta obra utiliza uma licença Creative Commons CC BY: https://creativecommons.org/lice 


\title{
VERSE AND TRANSLATION IN THE GOLDEN CENTURY
}

\begin{abstract}
This paper aims to illustrate how the multiple connections between poetry imitation, adaptation, and translation, can still be complicated and enriched by the use of different meters and stanzas in the reception literature. The examples are taken from XVIth century Spanish translators: Juan del Encina, Fray Luis de León and Francisco Sánchez de las Brozas (Virgil); Jerónimo de Urrea (Ariosto); Baltasar de Romaní and Jorge de Montemayor (Ausiàs March); Góngora and Francisco Faría (Claudianus).
\end{abstract}

Keywords: Poetry Translation; XVIth Century Spanish Poetry; XVIth Century Spanish Translations; Line; Stanza

\section{Verso e tradução}

Mais uma vez é necessário começar com Menéndez Pelayo. Ao tratar da originalidade das Coplas de Jorge Manrique em sua Antología de poetas líricos castellanos, o polígrafo de Santander discute e descarta, com bons argumentos, certo "paradoxo brilhante que com grande criatividade e autoridade quis dar crédito a D. Juan Valera" (Menéndez Pelayo (a) 396).$^{2}$ O paradoxo em questão surgiu da incrível semelhança entre a elegia de Manrique e uma elegia árabe composta anteriormente pelo poeta Abul-Beka, nascido em Ronda (Espanha). Valera, convencido da influência de Abul-Beka sobre Manrique, decidiu traduzir o poema árabe em sextilhas duplas de pé quebrado, isto é, adotou a estrofe de Manrique, convertendo uma afinidade tão notável como lógica (a sentença moralizante, o ubi sunt?, os exemplos de poderosos caídos em desgraça, o interesse pela realidade mais imediata...) em um parentesco tão atrativo quanto falso. Dom Marcelino Menéndez Pelayo advertia sobre isso com inteligência, "o quanto contribui à

${ }^{2}$ No original: "brillante paradoja que con su grande ingenio y autoridad quiso acreditar D. Juan Valera”.

Cad. Trad., Florianópolis, v. 40, $\mathrm{n}^{0}$ 1, p. 346-366, jan-abr, 2020. 
ilusão o uso de um mesmo metro" ${ }^{3}$, mas também pode acontecer o contrário, o de certas influências reais que são desfiguradas até ficarem imperceptíveis pelo uso de um metro diferente do original, ou pela aplicação de uma linguagem literária baseada em diversos princípios, com todo o seu trasladar de peculiaridades idiomáticas e também idiossincrásicas. Um bom exemplo podem ser os primeiros modelos castelhanos de um petrarquismo octossílabo e préGarcilaso, apenas reconhecível por olhos atentos. ${ }^{4}$

$\mathrm{O}$ verso tem, portanto, a capacidade de dificultar ou enriquecer as possibilidades de relação entre conceitos tão férteis para a literatura de qualquer época como os de imitação, adaptação e tradução, que já deram muitas mostras de pujança durante toda a Idade Média, desde as primeiras poesias em língua românica, que não passam de aljamias, até as provas do Quatrocentos "em forma itálica”, passando pela amplificatio de modelos únicos (Braulio, Grimaldo, Munio...) a cargo de versificadores talentosos como Gonzalo de Berceo, pela combinação de um texto de referência (o Alexandreis de Châtillon, no Libro de Alexandre, por exemplo) com outras fontes aproveitadas ocasionalmente por razões argumentais ou retóricas, ou pelo uso de uma linguagem diferente da sua na lírica culta peninsular dos Séculos XIII e XIV.

A vida da literatura é sempre uma vida de fronteira, e há poucos territórios mais ferozmente fronteiriços do que o da poesia do Século de Ouro, sedimentado sobre um conceito de imitação muito mais complexo e sofisticado que o anterior, e que não apenas foi assumido pelos teóricos, mas também aplicado detalhada e rigorosamente pelos criadores. Bastaria dar uma olhada no petrarquismo do Século XVI, em qualquer das línguas europeias (incluindo, obviamente, o Latim), para compreender a dificuldade de distinguir entre traduções, adaptações e imitações. É sabido e bem estudado que houve uma contribuição duplamente crucial, que devemos à

\footnotetext{
${ }^{3}$ No original: "lo mucho que contribuye a la ilusión el empleo de un mismo metro".

${ }^{4}$ Como os de Rico (1978); ver depois Recio (1996).
} 
amizade entre Juan Boscán (agora no papel de tradutor de Cortesano) e Garcilaso de la Vega, primeiros defensores de uma mudança que não foi apenas terminológica: "ele não chama a isto de romance, nem eu", diz Garcilaso, falando da tradução de seu amigo. ${ }^{5}$ Ao enfocar o verso, a obra poética do toledano envolveu um triplo processo de adaptação e naturalização: do petrarquismo (em seus sonetos e canções), do horacianismo (pela ode, elegías e epístola) e do bucolismo de raíz virgiliana (graças às três éclogas).

Onde se percebe melhor o grande salto estético e filológico pensado pelo Humanismo é precisamente na forma de recepção das éclogas de Virgílio, traduzidas por Juan de Encina por volta de 1492 e incluídas mais tarde em seu Cancionero. É assim que a interpelação inicial de Melibeu ressoa na primeira écloga: Tityre, tu patulae recubans sub tegmine fagi...

Títiro, cuán sin cuidado que te estás so aquesta haya, bien tendido e rellanado; yo triste, descarrïado, ya no sé por dó me vaya. ¡Ay, carillo!, tañes tú tu caramillo, no hay quien cordojo te traya. Yo, lacerado, aborrido, he dejado ya mi tierra, ando acosado y huido, y tú estáste aquí tendido a sabor por esta tierra, canticando por las silvas retumbando, no tienes quien te dé guerra. Cantas dos mil cantilenas de Amarilis, tu adamada, deslindándole tus penas,

${ }^{5}$ Ver o resultado de Ruiz Casanova (155-160). 
tus presiones y cadenas, tiénesla bien canticada, con reposo, a la sombra gasajoso, no te das nada por nada. ${ }^{6}$

Também é possível citar outro incipit muito famoso, o da écloga IX, Quo te, Moeri, pedes? an, quo uia ducit, in urbem?
¿Adónde aballas la pata, Meris?, dime la verdad, ¿dónde vas?, ¿dónde vas?, dímelo, cata, ¿vas de cara la ciudad?, di verás.

Encina, no segundo dos prólogos a sua tradução, diz que: "para não gerar aborrecimento aos leitores da minha obra, decidi trová-la em vários gêneros de métrica" (Cancionero, fol. XXXllr). ${ }^{7}$ Essa diversidade, apenas perceptível a um leitor atual e que já não seria muito evidente para um neto do próprio Encina, consiste em usar diversas estrofes de versos octossílabos (octavilhas, sextilhas, quintilhas e redondilhas, com presença variável de pé quebrado), mas sempre aplicando um critério expressivo coerenteconsistente com o estilo baixo ("rústico", diz o próprio Encina), atribuído às éclogas na famosa e ainda circulante roda virgiliana. A única exceção, tanto para fins métricos como estilísticos, é a tradução da

\footnotetext{
${ }^{6}$ Modernizo o texto pegando-o diretamente do fac-símile do Cancionero de 1496 (Madri, Real Academia Española, 1989, que por sua vez é reimpressão do de 1928), mais confiável do que algumas edições modernas (por exemplo, a edição de Rambaldo (I, 234), diz "recheado" no v. 3 e "quem" nos vv. 8 e 16).

${ }^{7}$ No original: "por no engendrar fastidio a los letores desta mi obra, acordé de la trovar en diversos géneros de metro".
} 
écloga IV: uma vez que é preciso lidar com "coisas importantes" (o próprio Virgílio menciona em sua invocação: "Sicelides Musæe paulo maiora canamus..."), Encina eleva o estilo e escolhe o metro mais sério ao qual pode recorrer, a arte maior do Labirinto de Juan de Mena ou de alguns decires do Marqués de Santillana.

\begin{abstract}
Musas de Sicilia dexemos pastores, alcemos las velas del nuestro dezir, razón nos convida aver de escrevir misterios más altos de cosas mayores, ni a todos agradan los grandes primores ni a todos tan poco las cosas palpables, cantemos estilo notable a notables y suene el menor allá con menores.
\end{abstract}

Este abismo expressivo entre a tradução da écloga IV e a das demais não é, certamente, justificável em termos de fidelidade filológica ao texto virgiliano. Além de tudo, Encina a concebe em louvor aos reis católicos e a aplica, como anuncia no argumento, "ao nascimento bem-aventurado do nosso iluminado príncipe Dom Juan". ${ }^{8}$ Entre outras metamorfoses, todas elas justificáveis se não as contemplamos com um olhar de hoje (o infante de Virgílio já tinha sido tradicionalmente identificado com Cristo), o cônsul Polião torna-se o rei Fernando o Católico e a deusa Lucina na Virgem Maria.

Graças, entre outras coisas, à mediação idealizada e de base humanística do bucolismo garcilasiano, essas traduções com adaptações abusivas serão impossíveis nos tempos de frei Luis de León e Francisco Sánchez de las Brozas. Vamos ouvir Melibeu outra vez, primeiro na versão do Brocense:

\footnotetext{
${ }^{8}$ No original: "al nacimiento bienaventurado del nuestro muy esclarecido príncipe don Juan".
} 
Títiro, so la encina reposando con tu flauta, la alegre cantilena estás a tu sabor ejercitando.

Mas ¡ay del que se parte a tierra ajena, huyendo de la suya desterrado, del dulce prado y de la selva amena!

Tú, Títiro, a la sombra recostado, enseñas a estas selvas deleitosas resuenen a Amarilis tu cuidado.

E a seguir na menos amplificada por frei Luis:

Tú, Títiro, a la sombra descansando de esta tendida haya, con la avena el verso pastoril vas acordando.

Nosotros desterrados, tú sin pena, cantas de tu pastora, alegre, ocioso, $\mathrm{y}$ tu pastora el valle, el monte suena.

O poeta da Vida retirada traduziu cinco éclogas em tercetos (I, III, IV, V e IX) e outras cinco em oitavas (II, VI, VII e VIII), mas tanto na sua versão, como na do Brocense, nota-se um contraste estilístico e filológico com a de Encina, que não precisa de comentários. ${ }^{9}$ Agora também não é necessário insistir na importância de frei Luis na história da tradução literária, mas pode ser útil ter em mente que a sua geração, que é também a do Brocense e a de Fernando de Herrera, desempenhou um papel decisivo na comunicação entre o petrarquismo e a poesia greco-romana (e a neolatina) ou na adaptação dos metros e dos gêneros clássicos (com

${ }^{9}$ Principalmente porque foi muito bem estudado por Bayo (1970) e porque contamos com análises linguísticas que comparam tais traduções, por exemplo a de Morreale (1989). 
suas confluências e polaridades). ${ }^{10}$ A partir do crescente interesse pela tradução poética, o grupo sevilhano reuniu-se em torno das Anotaciones herrerianas ou, de forma individual, por, Juan de Mal Lara, na Filosofía vulgar, onde ele oferece uma curiosa mistura de disseminação e experimentação através da tradução de numerosos fragmentos clássicos. ${ }^{11}$

\section{Dois exemplos de traduções de "línguas fáceis"}

Numa imprensa de Barcelona apresentaram um tradutor do italiano a Dom Quixote (II, 62): ${ }^{12}$

- Minha nossa, como vossa mercê está enfronhado no idioma toscano! - disse dom Quixote -. Sou capaz de apostar que, quando em toscano se diz piace, vossa mercê diz "agrada" em castelhano, e onde diz più, diz "mais", e a $s u$ chama de "acima" e giù, de "abaixo".

- Sim, senhor, com certeza - disse o tradutor -, porque essas palavras são equivalentes.

- Eu me atrevo a jurar - disse dom Quixote - que vossa mercê não é conhecido, porque o mundo é sempre inimigo de premiar os espíritos brilhantes e os trabalhos louváveis. [...] E traduzir de línguas fáceis nem prova talento nem bom estilo, como não o prova quem transcreve ou copia um texto de um papel para outro. Mas disso não quero inferir

\footnotetext{
${ }^{10}$ Para todos os efeitos ver os resultados das reuniões organizadas pelo Grupo P.A.S.O., em particular os dedicados à ode, à elegia e à epístola López Bueno (1993, 1996, 2000). O caso italiano, útil para as demais literaturas europeias, é estudada em Carrai (1999).

${ }^{11}$ É estudado por Osuna (1994). Uma visão de conjunto da tradução no Século de Ouro é oferecida em García Yebra (135-151), e um completo repertório em Ruiz Casanova (131-300).

12 [N.T] Para esta e as demais passagens referentes a Dom Quixote: Cervantes, Miguel de. Dom Quixote. Volume II. Tradução de Ernani Ssó. $5^{\text {a }}$ reimpressão. São Paulo: Penguin-Companhia das Letras, 2012.
} 
que o exercícios da tradução não seja louvável, porque o homem poderia se ocupar de coisas piores, que lhe trouxessem menos proveito.

É a mesma passagem em que aparecem outras duas frases muito repetidas, a comparação com a "tapeçaria flamenca" e o elogio, como exceções, dos "famosos tradutores" Cristóbal Suárez de Figueroa (pela sua versão do Pastor fido) e Juan de Jáuregui (por sua Aminta), mas tanto o cinismo de Dom Quixote com o suposto tradutor de umas supostas Bagattelle como a mais célebre sentença do padre durante o escrutínio (I, 6: os livros traduzidos "jamais chegarão ao ponto que os versos alcançaram no primeiro parto") apontam à tradução de poesia em língua vulgar, pois deixam expressamente de fora as versões "das rainhas das línguas, a grega e a latina”.

O menosprezo da tradução entre línguas vulgares era quase obrigatório nos textos humanísticos, mas as opiniões expressas no Quixote respondem, para começar, ao fato de que Cervantes e muitos outros espanhóis relativamente cultos (mesmo sem passar pelos terços da Itália, destino comum de muitos escritores) poderiam fazer suas as palavras do Cavaleiro da Triste Figura: "eu sei um pouco de toscano e me orgulho de cantar algumas estrofes de Ariosto". ${ }^{13}$ Mas além disso tendem a atacar as traduções da épica italiana, que representavam (e é um detalhe sociologicamente muito revelador) um tipo diferente de tradução, não impulsionada por motivos estéticos, criativos ou de combates humanísticos, mas também, ou acima de tudo, pela oportunidade editorial e comercial de satisfazer as necessidades do mercado e do público, um público que não é mais formado por escritores que entendem e recitam em italiano as incursões de Angélica, mas por leitores leigos, ávidos de aventuras de cavalaria em verso ou prosa.

É sintomática a proliferação de imitações e adaptações do Morgante de Pulci ou do Orlando furioso de Boiardo em obras como,

${ }^{13}$ Outro caso parecido era o de Jerónimo de Pasamonte (Riquer, (b) 115). 
apenas para citar um dos muitos exemplos possíveis, o Espejo de caballerías, ${ }^{14}$ e não é menos reveladora a decisão de traduzir em prosa obras tão notáveis pelo seu valor lírico, como o Orlando furioso de Ludovico Ariosto, convertido em prosa por Diego Vázquez de Contreras em 1585. Se nos detemos por um momento no caso dos tradutores de Ariosto, já bastante estudado, a tradução em verso também não era uma garantia de fidelidade. ${ }^{15}$

A primeira e mais difundida das traduções rimadas de Orlando furioso foi a de Jerónimo de Urrea, objeto incontestável das críticas dos personagens do Quixote e de outros contemporâneos de Cervantes. ${ }^{16}$ Só no século XVI ele conheceu uma dúzia de edições que apareceram em Antuérpia (a princeps em 1549 e outras duas em 1554 e 1558), Lion (1550 e 1554), Veneza (1553 e 1575), Barcelona (1564), Medina do Campo (1572), Salamanca (1578), Toledo e Bilbau (ambas em 1583). Além do desejo de preservar "doçura e primor" originais e acima de tudo (ou abaixo) o não muito proeminente talento poético de Urrea, seu conceito de tradução admitia e até exigia amplas liberdades. As intervenções modificadoras do tradutor, são tão numerosas e profundas que os estudiosos modernos conseguiram propor mais de uma taxonomia. Urrea eliminou boa parte do canto terceiro (o de exaltação da família d'Este), distorceu importantes episódios (entre eles o da viagem de Astolfo à lua) ao eliminar, por motivos religiosos, várias oitavas com alusões ao arcanjo São Miguel ou a São João Evangelista, adoçou ocasionais críticas aos espanhóis e, sobretudo, acrescentou muitas oitavas (es-

\footnotetext{
${ }^{14}$ Ver Gómez-Montero (1992).

15 Ver Chevalier (1966); na tese de doutorado, ainda inédita, de Luisa Gutiérrez Hermosa (97-136), pode-se ver um excelente estudo de conjunto, com uma completa bibliografia, das traduções de Ariosto no século XVI.

${ }^{16}$ Compare uma passagem da curiosa Resposta do capitão Salazar ao Bachiller de la Arcadia, uma vez citado por anotadores do Quixote: "E dom Jerónimo de Urrea, não ganhou fama como nobre escritor, e ainda, segundo dizem, muito dinheiro (o que importa mais), por ter traduzido Orlando o Furioso colocando apenas de sua casa, onde o autor dizia cavallieri, cavaleiros, e onde o outro dizia arme, ele colocou armas, e onde amori, amores (Paz e Melia, 89).
} 
pecialmente no canto XXXV) para incorporar em seu Orlando um elogio de diversos heróis dos quais Ariosto não tinha conhecimento. Hoje, esse comportamento nos surpreende e é filologicamente intolerável, mas era muito comum e respondia ao desejo interessado de traduzir efetivamente o elemento panegírico que, sem dúvida, o original continha. Além disso, tanto a atenuação das implicações religiosas quanto a hispanização de temas e personagens foram encontradas em outros tradutores do Furioso (como Hernando de Alcocer) e até mesmo no Jerusalém Libertada de Tasso, tema sobre o qual contamos com uma recente e exemplar pesquisa. ${ }^{17}$

Outro caso interessante é o de Ausiàs March, "sem dúvida o maior poeta literal europeu do século XV"18 (Di Girolamo (b) 9). ${ }^{19}$ As traduções antigas, pouco úteis para um leitor atual e reunidas por Martín de Riquer (1946) há mais de meio século, apresentam muitos equívocos que se devem frequentemente aos problemas de transmissão dos textos que, erratas aparte, afetam questões tão importantes como a disposição do cancionero ou a ausência de tornades. Apesar dessas deficiências e apesar da dificuldade de estabelecer na época os limites entre tradução, adaptação e imitação (na verdade, é frequente em imitadores ocasionais como Boscán, Garcilaso e Hurtado de Mendoza onde nos deparamos com as melhores traduções de algumas passagens antológicas), os tradutores do "Século de Ouro" nos legaram problemas e soluções profícuas.

A princeps da tradução de Baltasar de Romaní aparece em 1539, quando os hendecassílabos com cesura marcada (em quarta, ao modo de March), algumas rimas artificiais conservadas e os excessivos oxítonos a distanciam da musicalidade do hendecassílabo italiano que eventualmente prevaleceria na poesia em castelhano. A tradução de Jorge de Montemayor (1560), composta quando a

\footnotetext{
${ }^{17}$ A já citada de Gutiérrez Hermosa (1999).

${ }^{18}$ No original: "senza dubbio il piú grande poeta lírico europeo del quindicesimo secolo".

${ }^{19}$ Nestes parágrafos limito-me a apontar alguns aspectos que me parecem essenciais agora, mas para mais detalhes devemos ver a contribuição de Lluís Cabré neste mesmo volume ou no trabalho de Nogueras Valdivieso e Sánchez Rodrigo (1999).
}

Cad. Trad., Florianópolis, v. 40, n 1, p. 346-366, jan-abr, 2020. 
métrica italianizante já está totalmente naturalizada, é literariamente a melhor das antigas, mas o escritor português não pôde evitar idealizar a temática, petrarquizar as imagens e rebaixar ou preterir a conflitiva religiosidade do original. ${ }^{20}$ Em suma, essas duas traduções refletem perfeitamente o estado da poesia espanhola antes e depois do triunfo de Garcilaso. A tradução de Montemayor foi reeditada algumas vezes (em Zaragoza, 1562, e em Madrid, 1579) e foi bem importante para a leitura que as futuras gerações fizeram de March, que também prestaram seu tributo de admiração ao poeta valenciano com traduções ocasionais: enfatizam a que o Brocense fez por volta de 1580 e "ao pé da letra" do "Canto primeiro" (ou seja, o poema XXXIX), e as atribuídas talvez muito alegremente a Quevedo, entre elas a do Cant espiritual, que apresentam como particularidade a recuperação do octossílabo na linha da poesia religiosa barroca (por exemplo, a de José de Valdivielso).

\section{Uma mediação desconhecida: entre Góngora e Claudiano}

Montaigne nunca se cansou de confessar que Plutarco era um de seus autores de cabeceira, mas apenas "na tradução francesa" 21 (Essais, II, x), inclusive a despeito da difundida versão latina. O Plutarco de Montaigne foi o de Amyot, e o Plutarco de Mateo Alemán (relação apontada, porém um pouco mais, pelos estudiosos do Guzmán de Alfarache) foi o de Diego Gracián. A possível mediação de certos tradutores é um aspecto muito importante em que há muito a explorar, porque a versão de um clássico grego ou latino para qualquer uma das línguas vulgares não se limitava a garantir o provimento de temas, personagens ou ideias, mas participava diretamente na evolução do estilo literário, refletindo

${ }^{20}$ Há também bons estudos recentes da tradução de Montemayor: Gàlvez (2000) e Nogueras Valdivieso e Sánchez Rodrigo (2000).

${ }^{21}$ [N.T] Montaigne, Michel de. Ensaios. Tradução de Sérgio Milliet. São Paulo: Editora 34, 2016. p. 422. No original: “depuis qu'il est François”.

Cad. Trad., Florianópolis, v. 40, n 1, p. 346-366, jan-abr, 2020. 
suas tendências e mudanças ou exercendo uma influência real sobre autores concretos.

Algo assim aconteceu entre Claudiano e Góngora. Dom Luis conhecia muito bem, e obviamente em latim, toda a obra do autor do De raptu Proserpinae, porque nos chamados "poemas maiores" há diversos ecos, e quase todos já apontados pelos críticos, ${ }^{22}$ de diversos panegíricos, epitalâmios e poemas mitológicos do romano. Como no caso de outros autores tardios (penso em Silio Itálico), trata-se de uma influência bem conhecida mas pouco explorada, cujos primeiros sinais aparecem naqueles anos, cruciais para a evolução da língua poética (digamos que em torno de 1580), em que duas gerações se deram as mãos, porque temos notícia de duas traduções perdidas, uma de Fernando de Herrera ("em verso solto", segundo Francisco Pacheco) e outra de Lope de Vega, que a menciona como obra infantil (mas, como sempre nestes casos, entendida como juvenil) na Écloga a Cláudio. ${ }^{23}$
Vive sin luz, por ser en tierna infancia, el robo de la hermosa Proserpina, que a la pluma latina trasladé la elegancia; mas dedicada al cardenal Colona, por sirena quedó de su corona.

A perda imediata e irreparável do trabalho de dois tradutores tão significativos foi parcialmente compensada pelo aparecimento do Robo de Proserpina, na versão do granadino Francisco Faría (Madri, por Alonso Martín e à custa de Juan Berrillo, 1608), de quem pouco se sabe e quase nada foi dito desde o cervantino Viaje del Parnaso, II, 181-189:

${ }^{22}$ E reunidos por Gates (1937).

${ }^{23}$ Para Herrera, ver Macrí (1972, p. 66), e para Lopez, Beardsley (69-70). 
Este, que de la cárcel del olvido sacó otra vez a Proserpina hermosa, con que a España y al Dauro ha enriquecido,

verásle en la contienda rigurosa

que se teme y espera en nuestros días

(culpa de nuestra edad poco dichosa)

mostrar de su valor las lozanías;

pero ¿qué mucho, si es aquéste el docto

y grave don Francisco de Farías? $?^{24}$

Que eu saiba, nos tempos modernos, o único que tratou de mencionar e julgar Faría foi, mais uma vez, Menéndez Pelayo, que, mesmo sentindo aversão por Claudiano, considera que o trabalho de Faría merece "apenas... elogios" ${ }^{25}$ com a única exceção de "certos recursos culteranos que ele às vezes acrescenta."26 27 Talvez não

${ }^{24}$ Menéndez Pelayo ((b) 51) e Herrero García (498-499) compilam mais algumas notícias biográficas.

${ }^{25}$ No original: "solo... elogios".

${ }^{26}$ No original: "ciertos rasgos culteranos que a veces añade".

${ }^{27}$ Vale a pena ler o julgamento de dom Marcelino (se é que de fato a passagem lhe pertence, como se pergunta quem olha a página correspondente da "Edição Nacional" das Obras Completas): "Faría traduziu um original de gosto perverso; por isso não é de se estranhar que os defeitos do texto latino tenham passado à tradução. A presunção, a excessiva pompa, o tom estridente, todos os defeitos, enfim, da extrema decadência são fielmente reproduzidos na cópia. E o intérprete provavelmente não agiu de outra forma, sob pena de desfigurar a obra que traduzia. / Só temos elogios ao trabalho de Faría. Excluindo certos recursos culteranos que às vezes aumentam os grandes defeitos do poeta latino, a versão apresenta todos os méritos que poderia ter, o tom vivo e robusto, a elocução limpa e correta, a versificação galante e constante, embora ritmicamente pouco variada" (Menéndez Pelayo (b) 53). No original: "Faría tradujo un original de perverso gusto; por eso no es de extrañar que a la traducción hayan pasado los resabios del texto latino. La hinchazón, la excesiva pompa, el tono retumbante, todos los efectos, en fin, de la extrema decadencia se hallan fielmente reproducidos en la copia. Y no debió haber obrado el intérprete de otra manera, so pena de desfigurar la obra que traducía. / Nosotros sólo tendremos elogios para el trabajo de Faría. Aparte de ciertos rasgos culteranos que a veces añade a los grandes defectos del poeta latino, la versión presenta todos los méritos que podía tener, el tono brioso y ro- 
tenha havido na história preconceitos mais sábios e reveladores do que os de Dom Marcelino, que mesmo disparando para outro lado acertava sempre no alvo. Por isso vale a pena olhar mais atentamente para o volume de 1608 e terminar estas páginas completando o que foi dito na antiga Biblioteca de tradutores espanhóis (de onde são pinçadas de forma um pouco confusa algumas frases dos preâmbulos: as primeiras do privilégio de impressão e as últimas do prólogo). A continuação, segue o prólogo completo "Aos leitores".

Cuán difícil sea, en tanta diferencia de números, de voces y modos de decir como de un idioma a otro se conocen, traducir tan fielmente que la traducción agrade tanto como la obra principal, júzguelo el sabio a cuyas manos este mi trabajo llegare. Y si, como espero, le pareciere que he procedido con juicio, y obediente a los preceptos de los legisladores de este arte, sin desdorar el lustre, ornato y figuras de que usó Claudiano, y valiéndome de la frasi más propia de mi lengua materna, en premio de este cuidado le suplico defienda mi obra de los que arrojadizamente quisieren reprehender lo que yo con tanto estudio he deseado castigar. Bien quisiera ofrecer perfecto este estudio e intento que Claudiano dejó imperfecto y destroncado, mas confieso que me desanimó mi conocimiento propio, que no fío tanto de mí que pueda igualar lo que tan heroico y claro ingenio con alteza de estilo entendió. No faltará otro más capaz o más animoso que quiera acometer esta empresa, y yo quedaré contento con solo el nombre de traductor de obra tan insigne, que porque del todo no parezca inútil, quise exornar con dos sentidos alegóricos, uno moral, que pongo al principio de cada libro y traduje de italiano, y otro natural, que pondré al fin de la verdadera historia, y este dio ocasión a la ficción poética a que Claudiano se aplicó y yo ofrezco traducida. Vale, etc. ${ }^{28}$

busto, la elocución limpia y correcta, la versificación gallarda y sostenida, aunque rítmicamente poco variada".

${ }^{28}$ Robo de Proserpina, de Cayo Lucio Claudiano ... traduzido por ... Francisco Faría (Madrid, 1608), fol. \5 da nota preliminar; modernizo a ortografia. 
Ao contrário dos "versos soltos" que Herrera teria escolhido, Faría optou pela oitava, o canal habitual da poesia narrativa (no estilo dos romanzi italianos, mas também coerente com uma linha temática de caráter mitológico que remonta à écloga terceira de Garcilaso). Trata-se de uma tradução equilibrada e bem proporcionada, com uma média de pouco mais de dois hendecassílabos castelhanos para cada hexâmetro latino; no livro primeiro a amplificatio é ligeiramente maior (de 288 a 696 versos), mas a proporção dos livros segundo (de 372 a 792) e terceiro (de 448 a 936) é quase idêntica.

O Robo de Proserpina está repleto de expressões que seríamos tentados a considerar como tipicamente gongorinas (ainda que anteriores ao Polifemo e as Soledades) se não fossem o resultado da devida obediência a um autor latino que, além de estar entre os prediletos de Dom Luis, frequentou a narrativa de episódios mitológicos de ambientação siciliana ou a descrição de ninfas apaixonadiças, labutas campestres e ócios cinegéticos. É mera ilusão o ar pré-gongorino de expressões tais como "no côncavo escuro da terra" (fol. 8v; De raptu, I, 38), "e justo na lua de sua testa" (fol. 13v; De raptu, I, 129). Outras características de estilo nem sempre dependentes do original latino podem ser atribuídas à evolução dos costumes poéticos, como a abundância de versos bimembres, um dos recursos mais destacados da gongorina Fábula de Polifemo y Galatea.

Há também, é claro, muitas inovações de um tradutor que, quando tem que desviar um pouco da literalidade do original, está muito atento à evolução lexical e sintática da linguagem poética de seus contemporâneos, utilizando modismos e cultismos que não são difíceis de achar em outros poetas (entre eles, precisamente, Fernando de Herrera): fulminante, impetuoso, jovem, tempestuoso, luz duvidosa... Mas, algumas dessas inovações lexicais ou sintáticas são marcantes, tanto pelo seu distanciamento da letra do original quanto pela audácia expressiva que abarcavam/continham lá por 1608. É o caso de alguns cultismos de uso mais restrito não fomentados contextualmente por Claudiano, como caligino- 
so ("Reitor da região caliginosa", ${ }^{29}$ fol. $32 \mathrm{v}$, tradução bastante livre de De raptu, II, 214) ou iminente, frequente na poesia, mas raramente usado com o sentido de proeminência puramente física (e ainda anatômica) que tem no Polifemo, 49 ("um monte era de membros eminente" $)^{30}$ e em algumas passagens do Robo: “à cúpula chegou do monte Ida/onde estão os palácios eminentes" 31 (fol. 17r; De raptu, I, 202) e, principalmente, "humano o meio, o meio da serpente,/serpente o baixo e o homem o eminente" 32 (fol. $24 \mathrm{v}$; De raptu, II, 22-23). ${ }^{33} \mathrm{E}$ em algum momento nos deparamos inesperadamente com hipérbatos que excedem os herrerianos em violência, como o usado na tradução de uma passagem do segundo livro: "Depois que os cavalos apareceram/à não vista de seus olhos lume" 34 (fol. 31v; De raptu, II, 192-194).

Em suma, vários detalhes da tradução de Francisco Faría nos servem para tornar menos abrupto e mais compreensível o salto de ascensão que ocorre entre a linguagem poética de Herrera e a de Góngora. Assim, é bem provável que durante o processo de criação do Polifemo e das Soledades, na prodigiosa memória criativa de Dom Luis, repleta dos melhores latins de Horácio, de Ovídio e do próprio Claudiano, estivesse interposto também o eco de certas soluções expressivas da tradução castelhana do Robo de Proserpina publicada em 1608 pelo granadino Francisco Faría. Porém, talvez eu tenha tropeçado e caído no mesmo engano de Dom Juan Valera.

\footnotetext{
${ }^{29}$ No original: "Rector de la región caliginosa".

${ }^{30}$ No original: "un monte era de miembros eminente".

${ }^{31}$ No original: "a la cumbre llegó del monte Ida / donde están los palacios eminente".

${ }^{32}$ No original: "humano el medio, el medio de serpiente, / sierpe lo bajo y hombre lo eminente".

${ }^{33}$ Outros exemplos em Vilanova (1957, I, p. 444).

${ }^{34}$ No original: "Luego que los caballos asomaron / a la no vista de sus ojos lumbre".
}

Cad. Trad., Florianópolis, v. 40, n 1, p. 346-366, jan-abr, 2020. 


\section{Referências}

Bayo, Marcial José. Virgilio y la pastoral española del Renacimiento (14801550). Madrid: Gredos, 1970.

Beardsley, Theodore S. Hispano-Classical Translations Printed between 1482 and 1699. Madrid: Duquesne University Press, 1970.

Carrai, Stefano. I precetti di Parnaso. Metrica e generi poetici nel Rinascimento italiano. Roma: Bulzoni, 1999.

Cervantes, Miguel de. Dom Quixote. Tradução de Ernani Ssó. Volume II. $1^{\mathrm{a}}$ ed. São Paulo: Penguin Classics Companhia das Letras, 2012.

Chevalier, Maxime. L'Arioste en Espagne (1530-1650). Recherches sur l'influence $d u$ "Roland furieux". Burdeos: Institut d'Études Ibériques et Ibéro-Américaines de l'Université de Bordeaux, 1966.

Di Girolamo, Costanzo. "Traduire Ausiàs March". Llengua \& Literatura, [s.1], 8, 1997(a). p. 369-400.

Di Girolamo, Costanzo (ed.); March, Ausiàs. Pagine del Canzoniere. Milán: Luni, 1998(b).

Gàlvez, Jordi. "Lectura i recepció d'Ausiàs Marc a l'obra de Jorge de Montemayor". In: Martin, G.; Zimmermann, M.-C. Ausiàs March (1400-1459). Premier poète en langue catalane. París: Klincksieck, 2000. p. 345-355.

García Yebra, Valentín. Traducción: historia y teoría. Madrid: Gredos, 1994.

Gates, E.J. “Góngora's Indebtedness to Claudian”. The Romanic Review, [s.1], 28, 1937. p. 19-31. 
Gómez-Montero, Javier. Literatura caballeresca en España e Italia (1483-1542). El "Espejo de cavallerías" (Deconstrucción textual y creación literaria). Tubinga: Max Niemeyer, 1992.

Gutiérrez Hermosa, Luisa $\mathrm{M}^{\mathrm{a}}$. La "Gerusalemme liberata" en España. T. Tasso y sus traductores en el Siglo de Oro. Tesis doctoral. Barcelona: Universitat Pompeu Fabra, 1999.

Herrero García, Miguel (ed.); Cervantes, Miguel de. Viaje del Parnaso. Madrid: CSIC, 1983.

López Bueno, Begoña (ed.). La oda. Sevilla-Córdoba: Universidad de SevillaUniversidad de Córdoba, 1993(a).

López Bueno, Begoña (ed.). La elegía. Sevilla-Córdoba: Universidad de SevillaUniversidad de Córdoba, 1996(b).

López Bueno, Begoña (ed.). La epístola. Sevilla-Córdoba: Universidad de SevillaUniversidad de Córdoba, $2000^{\circ}$.

Macrí, Oreste. Fernando de Herrera. $2^{\text {a }}$ edición. Madrid: Gredos, 1972.

Menéndez Pelayo, Marcelino. Antología de poetas líricos castellanos, II. Santander: CSIC, 1944(a).

Menéndez Pelayo, Marcelino. Biblioteca de traductores españoles, II. Santander: CSIC, 1952(b).

Montaigne, Michel de. Ensaios. Tradução de Sérgio Milliet. São Paulo: Editora 34, 2016.

Morreale, Margherita. "Fr. Luis de León y Juan del Encina ante la 10ª égloga de Virgilio". In: Morón Arroyo, Ciriaco; Revuelta Sañudo, Manuel (eds.). Fray Luis de León. Aproximaciones a su vida y a su obra. Santander: Sociedad Menéndez Pelayo, 1989. 
Nogueras Valdivieso, E.J.; Sánchez Rodrigo, L. "Notas sobre la traducción de la poesía románica medieval: cuatro siglos de Ausiàs March". In: Paredes, J.; Muñoz Raya, E. (eds.). Traducir la Edad Media. La traducción de la literatura medieval románica. Granada: Universidad de Granada, 1999. p. 167-206.

Nogueras Valdivieso, E.J.; Sánchez Rodrigo, L. “Ausiàs March y Jorge de Montemayor: traducción e interpretación”. In: Martin, G.; Zimmermann, M.-C. Ausiàs March (1400-1459). Premier poète en langue catalane. París: Klincksieck, 2000. p. 357-374.

Osuna Rodríguez, $\mathrm{M}^{\mathrm{a}}$ Inmaculada. Las traducciones poéticas en la "Filosofía Vulgar” de Juan de Mal Lara. Córdoba: Universidad de Córdoba, 1994.

Paz y Melia, A. (ed.). Sales españolas o agudezas del ingenio nacional. Madrid: M. Tello, 1890.

Rambaldo, Ana María (ed.). Juan del Encina, Obras completas. Madrid: EspasaCalpe, 1978.

Recio, Roxana. Petrarca en la Península Ibérica. Madrid: Universidad de Alcalá de Henares, 1996.

Rico, Francisco. "De Garcilaso y otros petrarquismos". Revue de Littérature Comparée, [s.1], 52, 1978. p. 325-338.

Ruiz Casanova, José Francisco. Aproximación a una historia de la traducción en España. Madrid: Cátedra, 2000.

Riquer, Martín de. Traducciones castellanas de Ausias March en la Edad de Oro. Barcelona: Instituto Español de Estudios Mediterráneos, 1946(a).

Riquer, Martín de. Cervantes, Passamonte y Avellaneda. Barcelona: Sirmio, 1988(b). 
Vilanova, Antonio. Las fuentes y los temas del "Polifemo" de Góngora. Madrid: CSIC, 1957.

Recebido em: 15/07/2019

Aceito em: 20/10/2019

Publicado em janeiro de 2020

José María Micó. E-mail: josep.mico@upf.edu. ORCID: https://orcid.org/0000-0002-4116-8171 Andréa Cesco. E-mail: andrea.cesco@gmail.com. ORCID: https://orcid.org/0000-0002-4708-186X

Mara Gonzalez Bezerra. E-mail: mara.gonzalez.letras@gmail.com.

ORCID: https://orcid.org/0000-0001-8390-5910 